\title{
CHONDROBLASTOMA OF THE MAXILLA - A CASE REPORT
}

\begin{abstract}
:
A 27 year old female presented with swelling in the left cheek involving the maxilla, of seven months duration. Histopathological examination showed a lobulated tumour composed of large polygonal cells with distinct "chicken-wire" type of calcification around individual tumour cells. A diagnosis of chondroblastoma was made.
\end{abstract}

Key Words: Bone tumour, Chondroblastoma, Maxilla.

\section{INTRODUCTION:}

The commonest site of chondroblastoma is in the epiphysis of long bones. Chondroblastomas have also been reported in the skull bones. However, its occurrence in the maxilla is very rare.

\section{CASE HISTORY:}

A 27 year old female patient presented with a history of toothache and swelling of the left cheek of seven months duration. The swelling was found to be increasing in size since three months, even after the offending tooth was extracted.

On examination, there was a firm to hard mass over the left maxilla about $7 \mathrm{~cm}$ in the greatest dimension. The patient did not have trismus. Cranial nerves - III, IV \& VI were normal. Vision was unaffected. X-ray showed tumour in the left maxilla. The tumour was biopsied and the material was sent for histopathological examination.

\section{PATHOLOGY:}

Gross examination: Grossly the specimen consisted of two bits covered by mucosa, the larger one measuring 1 x 0.6 x $0.4 \mathrm{~cm}$. The smaller bit was partly ulcerated.

Microscopic examination: Sections showed a lobulated tumour composed of nodules of large polygonal cells with moderate amount of pale to eosinophilic cytoplasm with distinct cytoplasmic borders and large round to oval vesicular nuclei with single basophilic nucleoli (Fig.1). No nuclear grooves were seen, but distinct "chicken-wire" type of calcification was seen around individual tumour cells in areas (Fig.2). Islands of eosinophilic hyaline chondroid with patchy calcification were seen (Fig.3). Scattered osteoclastlike material, granulation tissue, thin- walled vessels and cystically dilated vascular spaces reminiscent of an aneurysmal bone cyst were seen.

Special stains: PAS: Scanty focal positivity for glycogen.

Reticulin: Deposition around individual cells in a "honeycomb" pattern. A diagnosis of "Chondroblastoma" was made.

DISCUSSION: 
Chondroblastoma is a benign chondroid neoplasm that occurs predominantly in the second decade of life. There is a slight male predominance and any bone in the skeleton may be involved, although most occur at the ends of the long bones. The majority of chondroblastomas occur in the epiphysis, although an occasional typical chondroblastoma occurs in the metaphysis. Patients with involvement of temporal bone tend to be older than patients with involvement of long bones. ${ }^{2}$ In our case, the tumour was located in the maxilla. Chondroblastomas involving the skull and facial bones have been reported. In a series of 30 chondroblastomas, which were reviewed, 21 were located in the lateral part of temporal bone, six in the mandible, 1 in parietal bone and 2 in the region that included the temporal bone and mandible. ${ }^{3}$ One case of chondroblastoma located in the maxilla has also been reported. ${ }^{4}$

Histologically, chondroblastomas must contain two basic cell types - the chondroblast and the osteoclast like giant cell. The chondroblast is a polygonal cell with distinct cell borders. Most of the cells contain a single nucleus. The nucleus is round, oval or slightly indented or lobulated and fills about one half of the cell. Mitosis is variable. The cytoplasm is granular and deep pink and has rounded sharp borders. The cells contain variable amounts of glycogen. Giant cells sprinkle the non-chondroid areas. The lesion must contain islands of primitive chondroid, fibrochondroid or hyaline cartilage. The chondroblastoma is also typified by the deposition of calcium. The unusual "chicken-wire" type of calcification around individual cells is characteristic of chondroblastoma. ${ }^{5}$

In our case, the tumour was composed of lobules of chondroblasts admixed with islands of eosinophilic hyaline chondroid and scattered osteoclast-like giant cells.

The typical "chicken-wire" type of calcification was seen around individual tumour cells. The differential diagnosis includes giant cell tumour, chondromyxoid fibroma and clear cell chondrosarcoma. Giant cell tumours occur in slightly older age group. They are composed of masses of prominent osteoclast-like giant cells and ovoid spindly stromal cells. The presence of chondroid differentiation and the typical "chickenwire" type of calcification are not seen in GCT. Chondromyxoid fibroma shows lobules of spindle or stellate shaped cells in a myxoid background. Typically the center of the lobule is hypocellular and the periphery is hypercellular. Clear cell chondrosarcomas are lobulated tumors with cells showing strikingly clear cytoplasm. This feature distinguishes is from chondroblastoma.

\section{CONCLUSION:}

A diagnosis of chondroblastoma has to be considered in tumours arising from the maxilla, though the site is unusual. This has to be done after meticulously ruling out other possibilities like giant cell tumour, chondromyxoid fibroma and clear cell chondrosarcoma.

\section{ACKNOWLEDGEMENT:}

We sincerely thank Dr. Mike Smith, Surgeon, Department of ENT, Western Regional Hospital, Pokhara for providing this surgical specimen.

\section{REFERENCES:}


1. Krishnan Unni K: Bone Tumours: in Diagnostic Surgical Pathology: Vol.1: second edition: Ed: Stephen S Sternberg: Lippincott - Raven: 1996:282.

2. Unni K.K., Inwards C.Y.: Tumours of the Osteoarticular system: in Diagnostic Histopathology of Tumours: Vol.2: Ed: Christopher D.M. Fletcher: Churchill Livingstone: 1996:1109 \& 1111.

3. Bertoni F., Unni K.K., Beabout J.W. et al: Chondroblastoma of the Skull and Facial bones: Am J Clin Pathol: 1987:88(1): 1-9.

4. Badia D.M., Vallogini P, Marinelli $\mathrm{M}$ et al: Benign Chondroblastoma localsed in the maxilla: Stomatol-Mediterr: 1985: 5(1): 75080. (Italian - Source: medline)

5. Joseph M. Mirra: Bone Tumours - Diagnosis and Treatment: J.B. Lippincott company: 1980: 186, 222-224 and 344. 